\section{Paulo Emílio Salles Gomes: a compreensão da realidade brasileira através da crítica de cinema}

João Carlos Soares Zuin ${ }^{1}$

Resumo: O objetivo deste artigo é compreender o papel intelectual desempenhado por Paulo Emilio Salles Gomes na sociedade brasileira. Partindo da análise da sua crítica de cinema no jornal O Estado de São Paulo, nos anos 1950, busco caracterizar o processo de construção do empenho político e cultural voltado para a construção de uma sociedade democrática no Brasil, que se desdobrava nas análises sobre o cinema, e a realidade brasileira nas décadas de 1960 e 1970.

Palavras-chave: Paulo Emílio Salles Gomes, Modernidade, Empenho Político e Cultural, Crítica de Cinema.

O ponto exclamativo, quando se afrouxa, torna-se interrogativo.

S. J. Lec

A participação de Paulo Emílio Salles Gomes no "Suplemento Literário" do jornal O Estado de São Paulo marca um momento importante na sua trajetória intelectual. Contratado para escrever semanalmente a coluna de cinema, realizou o desejo de refletir e compartilhar com o leitor o seu juízo cinematográfico, entre 1956 e 1965. Situando a sua extensa produção intelectual, podemos destacar a presença de quatro conjuntos de questões: 1 ) as reflexões sobre o cinema francês, russo, alemão, norte-americano, japonês, italiano, que eram elaboradas mediante um acontecimento específico: data comemorativa, criação de uma retrospectiva, exposição pública, palestra promovida por instituições cinematográficas nas cidades de São Paulo e do Rio de Janeiro; 2) as análises que realizou sobre a produção cinematográfica de Sergei Eisenstein, René Clair, Jean Renoir, David W. Griffith, Frederico Fellini, Roberto Rossellini, Vittorio De Sica, Charles Chaplin, Orson Welles e dos críticos André Bazin e Erich von Stroheim; 3) o seu empenho político e cultural voltado para a existência da cinemateca e da cultura cinematográfica brasileira; 4) o início da elaboração de uma crítica sistemática sobre a importância do cinema brasileiro, que surgia concomitante com o seu desejo de
1. Professor do Departamento de Sociologia da UNESPAraraquara.

E-mail: zuin@fclar. unesp.br 
querer historiar a formação do cinema nacional. É possível dizer que, no interior de tais questões, Paulo Emílio Salles Gomes desempenhou com maior vivacidade a vontade de compreender a especificidade da nova arte, buscando sempre capturar o sentido da mensagem em cada filme, para problematizá-la e revelá-la ao leitor. Por outro lado, é preciso destacar o esforço dirigido para a tarefa de democratização da cultura no Brasil, fruto do olhar atento do crítico que, ao refletir sobre as dificuldades de existência do cinema e das instituições cinematográficas no país, pensava com maior profundidade os dilemas e as contradições da sociedade atrasada e dependente em que vivia.

Buscamos alcançar três objetivos, nesse artigo, desenvolvidos através da análise da sociologia do conhecimento e da importância da avaliação do sentido e significado que as ideias têm na história. Primeiramente, analisaremos a maneira como Paulo Emílio Salles Gomes utilizou a crítica de cinema para desdizer ideias e valores que imperavam na vida social e que impossibilitavam o fluxo da cultura no Brasil, procurando contribuir para a existência de novos valores e ideias, mentalidades e comportamentos, princípios e instituições culturais. Posteriormente, procuramos acompanhar o curso do empenho cultural e político de Paulo Emílio Salles Gomes na investigação ensaística das desventuras do cinema brasileiro e da necessidade de compreendê-lo como manifestação da dependência e do subdesenvolvimento. Por fim, intentamos demonstrar que a evolução do seu pensamento crítico sobre o cinema e, especialmente do cinema brasileiro, sempre esteve acompanhada da percepção que manteve, ao longo de sua vida, da função do intelectual na formação de uma nação atrasada e subordinada à dinâmica do capitalismo. Se, por um lado, o empenho cultural e político que desenvolveu por meio da análise do cinema buscava potencializar a possibilidade técnica e estética da nova arte em refletir e explorar a totalidade do mundo visível e das dinâmicas profundas existentes no fluxo da cultura, por outro, procurava estimular e dinamizar a movimentação da imaginação e da consciência de si do povo brasileiro.

\section{A Crítica de Cinema de Paulo Emílio Salles Gomes}

A composição de sua crítica de cinema no "Suplemento Literário" surgia através da ligação que tecia entre as experiências vivenciadas, as ideias e os conceitos das modernas ciências humanas, com o seu empenho político e cultural, o que possibilitava a construção de um alcance científico e coletivo aos seus argumentos. Como afirmou Antonio Candido, mesmo deixando de ser um militante político após o desfecho do processo de redemocratização em 1946, Paulo Emílio Salles Gomes "sempre foi um homem visceralmente político, capaz de politizar qualquer atividade" (CANDIDO, 1986, p. 67). De fato, a especificidade da 
crítica de cinema de Paulo Emílio Salles Gomes está contida na essencialidade da ação política em sua vida e na capacidade intelectual que possuía em questionar politicamente os mais variados e dispersos elementos da vida e da dinâmica social. É o que podemos observar em uma precisa síntese acerca do sentido da sua crítica de cinema no jornal O Estado de São Paulo:

Qualquer atividade humana comporta luta e polêmica, mesmo o comentário inocente de assuntos cinematográficos. Eu associo minhas tarefas jornalísticas à batalha de que participo pela cultura cinematográfica brasileira em geral, e, mais particularmente, pela constituição de uma cinemateca em nosso país. (GOMES, 1982a, p. 161)

É importante destacarmos o sentido das palavras "luta" e "batalha", pois, como veremos, Paulo Emílio Salles Gomes empenhou-se profundamente nos embates que travou com órgãos públicos, para criar as condições objetivas necessárias para a existência da cinemateca brasileira, procurando estabelecer regulamentações, solicitando subsídios nas repartições públicas, combatendo as debilidades físicas das instalações que impediam a conservação dos filmes. Uma luta que se desdobrava na criação de associações civis de cinema e na difusão da cultura cinematográfica nas cidades brasileiras.

É sempre possível observarmos, na sua crítica de cinema, a capacidade em transformar os assuntos mais variados do cotidiano em problemas sociais. Na coluna intitulada "Cinemateca e Obstinação", escrita na atmosfera cultural de otimismo que passava o Brasil, no final dos anos cinquenta (a vitória na copa do mundo de futebol em 1958, o desenvolvimento econômico, o início da construção de Brasília), Paulo Emílio Salles Gomes procurou informar ao leitor a contínua destruição química dos primeiros filmes que retrataram a vida social brasileira no início do século XX, para que este pudesse se posicionar a favor da construção de uma instituição pública, a cinemateca brasileira. Sua intenção era chamar a atenção do leitor para participar do obstinado esforço pessoal e coletivo voltado para a criação da cinemateca:

O grupo que há quase vinte anos teve a idéia de fundar uma cinemateca em São Paulo e há dez anos se esforça quotidianamente em constituir a Cinemateca Brasileira encontra-se numa situação semelhante à dos brasileiros dos fins do século XVIII e primórdios do XIX interessados em criar uma biblioteca nacional, um arquivo e museu histórico e de belas-artes, um jardim botânico (...). Na realidade a nossa ação é animada pela certeza objetiva de que está na hora de existir uma 
cinemateca no Brasil e pela convicção de que ela existirá hoje ou amanhã, diretamente ou não ligada ao nosso empenho. (GOMES, 1982a, p. 73, grifo meu)

A argumentação, que buscava colher os vários problemas que afetavam a existência da cinemateca brasileira, foi composta mediante dois planos analíticos interligados entre si: o da possibilidade da existência objetiva e institucional e o da capacidade subjetiva dos indivíduos em compreenderem a importância do cinema na preservação dos filmes que refletiam as imagens do passado brasileiro, bem como na exibição dos diversos aspectos da sociabilidade no cotidiano. Diagnosticava as diversas constrições objetivas que impediam a existência e manutenção da cinemateca: a repressão ao Clube de Cinema, em São Paulo, efetuada pelo Departamento de Imprensa e Propagando do Estado Novo, nos anos 1940; a fragilidade das associações e fundações civis em existir, manter e conservar os filmes antigos; o não cumprimento da lei que previa o estabelecimento de convênios entre o município de São Paulo e as entidades civis que exibissem e conservassem filmes; a ineficácia da lei que permitia o auxílio à produção de filme brasileiro e o desenvolvimento da cultura cinematográfica. Uma descrição que ganhava maior força analítica através da narrativa das profundas limitações subjetivas existentes na percepção dos indivíduos acerca da conservação dos filmes: a incompreensão axiológica sobre a importância da manutenção da memória do passado registrada pelos filmes antigos, que eram corroídos pela decomposição química; a falsa simpatia daqueles que se solidarizam, sem efetivamente agir e contribuir para a construção de uma nova instituição cultural pública.

O objetivo das análises das constrições de ordem objetiva e subjetiva era expor as contradições existentes na sociedade, que estava se modernizando economicamente, e a permanência da precariedade dos projetos para conservação e desenvolvimento da cultura nacional. Não é um mero acaso que utilizou, por duas vezes, no artigo, o termo político e cultural italiano impegno, empenho, para denominar o sentido de sua ação e de seus colegas da Revista Clima e da Cinemateca de São Paulo. Uma postura que era própria de uma geração que compreendeu a necessidade imperativa da "crítica que analise as condições e as tendências atuais", que "propagandize e eduque, expandido um pouco mais toda a atividade intelectual que ainda se fecha em pequenas elites privilegiadas de espírito" (MACHADO, 1945, p. 27). Uma posição social própria de uma geração nascida na era das mudanças sociais e das revoluções, das ditaduras e dos regimes totalitários, das crises econômicas e das guerras mundiais, e que compreendeu que a "preocupação fundamental, entretanto, tanto no plano teórico como no prático, é com os problemas brasileiros"(GOMES, 1945, p. 290). 
Uma geração que afirmou a necessidade de novos valores e ideias para combater as velhas forças do passado e as novas forças sociais, mas que também soube posicionar-se perante um "dado fundamental: o Brasil é uma nação pobre. 0 reconhecimento de nossa pobreza como nação, é que nos dá um sentimento de responsabilidade ao qual não fugiremos" (GOMES, 1978, p. 18).

O empenho pela construção da cinemateca brasileira aparece como um dos principais problemas desenvolvidos pelo crítico de cinema. A reflexão acerca da importância da cinemateca surgia através dos mais variados assuntos: revelando e combatendo a má formação cultural da sociedade brasileira; liderando manifestações por sua existência efetiva; denunciando o descaso dos poderes públicos para com a cultura; cobrando o cumprimento das leis votadas e aprovadas que favoreceriam a cinemateca; expondo o estado de decomposição irreversível dos filmes guardados sem recursos e em instalações precárias; apelando para a sensibilidade do leitor com a intenção de estimulá-lo para que participasse da luta pela conservação de sua memória e de seu passado registrado nos filmes que ainda permaneciam conservados; anunciando exposições, retrospectivas e estudos sobre filmes. Nas várias formas do mesmo, sempre procurou afirmar uma forte convicção: a importância do cinema como expressão direta da vida social, uma arte cuja estética poderia promover, no espectador, um reencontro cognoscitivo e emotivo com sua mentalidade e comportamento, e com a lógica da realidade social.

São muitas as colunas em que refletiu sobre os motivos que impediam a efetiva existência da cinemateca no Brasil. Trata-se de um momento muito singular na sua trajetória intelectual, marcado pelo desejo de realização do projeto que se iniciara nos anos 1940, quando então colaborava para "ampliar o esforço pela cultura cinematográfica, atualmente limitado aí em São Paulo e ao que escreve aqui no Rio o Vinícius", conforme afirmara seu mestre em cinema Plínio Sussekind Rocha, na Revista Clima (ROCHA, 1941, p. 84). Um projeto cultural que o jovem crítico tentou desenvolver no interior da ditadura do Estado Novo, seja por meio de sua atividade como crítico de cinema, na Revista Clima, seja nos esforços voltados para a fundação do Clube de Cinema de São Paulo. No depoimento concedido a Cláudio Kahns, nos anos 1970, Paulo Emílio Salles Gomes destacou a importância do cinema e do Clube de Cinema para a formação intelectual de sua geração:

Dei a idéia para o grupo, de montarmos um clube que ficou sendo o "Clube de Cinema de São Paulo", a diretoria do clube era o Lourival, o Décio, o Cícero e eu. Nas sessões, distribuíamos programas mimeografados, e a gente tinha muita documentação sobre os filmes, que eu tinha trazido da França, o que ajudava bastante. Os professores estrangeiros 
que davam aulas na USP, se interessaram muito pelo Clube. Nas apresentações, os textos eram lidos em francês. Jean Maugüé, um notável professor de História da Filosofia que formou muita gente naquela época, lia os textos e freqüentemente após as sessões, as discussões eram feitas em francês. Quando começamos a fazer estas sessões, havia um interesse enorme por parte da imprensa. Os jornais davam notícias das sessões em manchetes (...). O Clube ia muito bem, com um enorme sucesso. Um dia, em 1943, chegou um delegado do DIP (Departamento de Imprensa e Propaganda) e apreendeu as cópias dos filmes. Era preciso pagar multa, porque, segundo o delegado, era muito estranha esta história de algumas pessoas se reunirem para ver filmes mudos antigos. Só podia ser coisa de subversivos. Como era preciso pagar a multa para reabrir o Clube, fui ao Rio falar com Israel Santos, que era o tal delegado do Rio. Foi uma conversa inesquecível: "Vocês passam por exemplo uma fita russa que aparentemente não tem nada de político; um documentário sobre uma fazen$\mathrm{da}$, onde de repente aparece uma mulher gorda dando de mamar a seu filinho, bonitinho, gordinho. Bem, como todo mundo sabe, as pessoas lá morrem de fome e, portanto, subrepticiamente, se passa propaganda comunista, sabemos que isto é propaganda comunista". Bem, então o Clube morreu, não houve jeito, mas continuamos a fazer as projeções em casa de pessoas. Na Revista Clima continuávamos com os artigos. (KAHNS, 1977, p. 22)

Podemos observar, no longo depoimento, a marca da desventura que a sua geração sofreu, ao ter que se desenvolver intelectualmente no interior de um Estado ditatorial e de uma sociedade civil frágil e refratária aos valores oriundos da modernidade e das modernas concepções de mundo. Dilema maior de uma geração, que Antonio Candido assim sintetizou: "passamos juntos por muita mudança, lutamos horas sem conta em lutas sem perspectivas, esperamos sem esperança colheitas que não brotaram, ficamos homens numa ditadura e enveIhecemos noutra" (CANDIDO, 1993, p. 196). No infortúnio que cerca o intelectual empenhado em combater tal rígido princípio da realidade, nas suas várias formas, como a estreiteza mental e valorativa, o autoritarismo e o golpismo, o elitismo e a rigidez dos costumes, como pode o intelectual realizar seus imperativos morais e políticos senão através da atividade crítica? É nesse sentido que podemos observar a ênfase do empenho político e cultural desenvolvido por Paulo Emílio Salles Gomes no "Suplemento Literário": 
O abandono do patrimônio cinematográfico brasileiro tem algo de monstruoso. Durante algumas décadas esse fenômeno, para nós cada vez mais estranho, era o produto de uma inconsciência generalizada à qual só escapavam alguns raros indivíduos de elite, como Roquete Pinto, dotados de imaginação e espírito científico. Melancólico e desanimador é averiguar, que uma instituição como a Cinemateca Brasileira assiste, há mais de doze anos, tolhida pela falta de meios de ação, à destruição acelerada de filmes que exprimem não só alguns momentos da vontade brasileira de fazer cinema, mas também refletem e ilustram a nossa evolução social. (GOMES, 1982a, p. 148)

O cinema não era, para o crítico, apenas uma nova forma de arte, muito menos um meio de entretenimento e diversão das massas urbanizadas. Paulo Emílio Salles Gomes compreendia o cinema como uma arte e uma forma de conhecimento que poderia permitir tanto uma nova reelaboração do passado por meio das imagens, quanto a construção de uma nova tomada de consciência histórica no interior da sociedade brasileira e do mundo. É possível dizer que Paulo Emílio Salles Gomes compreendia a importância do cinema de uma forma semelhante àquela desenvolvida por Siegfried Kracauer, que afirmava "o filme como espeIho da sociedade atual" (KRACAUER, 1982, p. 85), o que possibilitava a contínua exploração "dos dados físicos e, partindo deles, abre-se o caminho até algum problema ou convicção" (ibidem, p. 378). Se, para Kracauer, o "cinema torna visível o que não vemos" e, com ele, "resgatamos o mundo de seu estado letárgico", através das imagens é possível "apreender os objetos e acontecimentos que compreendem o fluxo da vida material" (ibidem, p. 368), para Paulo Emílio Salles Gomes, o cinema possuía a qualidade de "atualizar o passado", "recuperar o passado", mas também é sua especificidade construir, com liberdade, um "tempo equívoco e mágico (...) onde se encontram indiferenciados, como no espírito humano, o passado, futuro e presente" (GOMES, 1982, p. 52). Em ambos os críticos, podemos observar a ideia de que o cinema é tanto uma arte e um instrumento capaz de estimular a compreensão da dinâmica da vida social moderna, bem como um meio que possibilita e contribui para efetuar a superação das contradições existentes no tempo e no espaço social.

É importante marcarmos, aqui, um passo decisivo dado por Paulo Emílio Salles Gomes, no final da década de 1950. Partindo do sentimento de decepção quotidianamente renovado - aprofundado pelo incêndio da Cinemateca Brasileira, em 1957, que destruiu integralmente a fototeca, a biblioteca, a coleção de aparelhos e um terço do acervo de filmes -, o crítico de cinema construiu, progressivamente, novas interrogações acerca dos motivos culturais e 
políticos que impediam a existência de novos valores, princípios e instituições na sociedade brasileira. Na coluna intitulada "Variações Municipais", destacou que "o desejo de escrever é basicamente a procura de compensação para atos frustrados" e completou a análise informando ao leitor que "muitas vezes vi essa idéia enunciada, mas só agora reconheço sua plena justificação" (GOMES, 1982, p. 453), expondo-se, sem reservas, na condição de intelectual derrotado no campo político. Se os desejos pessoais e coletivos não podiam adquirir existência concreta na realidade social, procurou manter acesa a chama da vontade de ação e do espírito de luta nas colunas do "Suplemento Literário". Buscou realizar algo mais do que resta aos intelectuais numa situação política desfavorável, na medida em que continuou a exercer o juízo crítico voltado para racionalizar o irracional (uma operação mannheimiana presente em boa parte dos trabalhos intelectuais dos membros da sua geração), procurando compreender sempre mais profundamente o sentido das diversas "barreiras ao mesmo tempo absurdas, injustas e intransponíveis" (GOMES, 1982, p. 453), que enrijeciam os limites da realidade brasileira.

Em “A vez do Rio", coluna publicada no "Suplemento Literário", em 1958, escrevendo sobre o intuito da criação de uma cinemateca na cidade do Rio de Janeiro, colocou em destaque a necessidade de "nos interessarmos sistematicamente pela velha literatura cinematográfica brasileira que se encontra perdida nas coleções de jornais e revistas" (GOMES, 1982, p. 430). Convidando os interessados pelo cinema para olharem atentamente a existência da sua cultura cinematográfica, através do contato com as revistas e jornais dos anos 1920 e 1930, Paulo Emílio Salles Gomes desdobrava o empenho político e cultural dirigido para a edificação das instituições cinematográficas, no desejo de estudar sistematicamente a formação da cultura cinematográfica no Brasil: "não vejo outra forma de se conferir à cultura cinematográfica entre nós certo grau de encarnação senão esforçando-nos em tomar consciência de uma tradição que existe, e nela nos inserindo" (GOMES, 1982, p. 431). Despertava, assim, no crítico de cinema, o desejo de compreender sistematicamente a formação do cinema no Brasil. Doravante, toda a sua produção intelectual será cada vez mais marcada por essa escolha que constituiu o sentido maior do seu empenho político e cultural.

"Decepção e Esperança" é o título da coluna publicada no início de 1960, na qual reafirmou a importância do entendimento do cinema brasileiro, bem como ressaltou a necessidade de um estudo mais profundo sobre o cinema de Humberto Mauro, tema de sua tese de doutorado, que defendeu no início dos anos 1970. São vários os problemas desenvolvidos pelo crítico de cinema: o abandono do patrimônio cinematográfico e a inexistência da pesquisa histórica cinematográfica brasileira, a ausência nas elites da reflexão acerca da importância dos 
filmes que expressam a vontade de realizar o cinema no Brasil. Contudo, há um argumento central que servirá de base para toda sua reflexão sobre cinema nos anos 1970, período no qual Paulo Emílio Salles Gomes aprofundou sua capacidade de colher as contradições e paradoxos acumulados na sociedade brasileira: o conceito de formação que irá emprestar do amigo Antonio Candido, para compreender a especificidade histórica e cultural do cinema brasileiro, e a aversão que sente o brasileiro pelas imagens que refletem e revelam a sociabilidade em suas formas de vida e modos de existência, comportamentos e realidade física:

No prefácio da sua Formação da Literatura Brasileira, Antonio Candido lembra que um francês, um italiano, um inglês, mesmo um russo e um espanhol, não precisam sair de suas respectivas literaturas para elaborar a visão das coisas, experimentando as mais altas emoções literárias, ao passo que um brasileiro precisa. Se aplicássemos esse modo de pensar à arte cinematográfica, provavelmente concluiríamos que só a um norte-americano seria admissível uma experiência assim exclusiva; e, quanto ao brasileiro, seria compelido com desprazer a opinar pela incompatibilidade entre o gosto das altas emoções cinematográficas e a freqüência ao cinema nacional. Na realidade, em nosso País, o espectador habitual, que simplesmente procura emoções cinematográficas médias, foge dos filmes brasileiros (...). Na apreciação do passado do nosso cinema, a opção otimista tinge-se de sentimentalismo. Quanto a mim, não me furto a esse estado de espírito, e aplico à cinematografia brasileira as palavras de Antonio Candido sobre a nossa literatura: Se não for amada, não revelará sua mensagem, e se não amarmos, ninguém o fará por nós. Cabe, acrescentar que, no cinema, ainda muito mais do que nas outras formas de expressão artística, os critérios propriamente estéticos estão longe de exaurir os ângulos de interesse de uma obra. Convém lembrar, ainda, por menos agradável que se considere a asserção, que o cinema brasileiro nos exprime e revela. (GOMES, 1982a, p. 150, grifos do autor)

Paulo Emílio Salles Gomes utilizou da ideia e do modelo explicativo de formação para também compreender o sentido da relação existente entre os produtores de cinema, os meios de difusão e exibição e os espectadores. 0 diagnóstico revela que o cinema brasileiro que existia não conseguia formar um sistema de produção (que fosse capaz de construir um denso caráter coletivo na produção industrial cinematográfica), e, sobretudo, a sua posição subordinada ao juízo de gosto que plenamente aceitava a qualidade do cinema 
estrangeiro. Na atmosfera cultural e política dos anos 1960, marcada pelo forte desejo de libertação do mal acabado processo de formação nacional, Paulo Emílio Salles Gomes refutou a costumeira visão negativa do cinema nacional.

Podemos dizer que estava em curso um processo de superação das convicções exclamativas a respeito da mediocridade do cinema produzido no Brasil, para dar lugar a uma nova posição fincada na reflexão acerca dos motivos que impediam a efetivação do cinema brasileiro como um sistema. É nesse sentido que utilizamos, como epígrafe, o aforismo de Stanislaw Jerzy Lec ("o ponto exclamativo, quando se afrouxa, torna-se interrogativo"), pois, nos anos 1960, Paulo Emílio Salles Gomes rompeu definitivamente com os pré-juízos negativos que reinavam sobre o cinema nacional, e empenhou-se profundamente na tarefa de decifrar os motivos da aversão popular ao cinema feito no Brasil. Na importante coluna denominada estrategicamente "Um Mundo de Fiç̧ões", descreveu o problema com muita ironia, associando a "crônica incapacidade de existir" do cinema brasileiro com a sua inexistência como produto nacional, aludindo que o mesmo fato outrora ocorrera com o palito, a manteiga e o automóvel, produtos importados e manufaturados por povos estrangeiros:

O número de pessoas que se interessa pelo assunto cinematográfico brasileiro foi sempre muito reduzido. Para entendermos esse fenômeno, é preciso lembrar que até há bem pouco tempo reinou entre nós, muito generalizada, uma mentalidade essencialmente importadora. No primeiro volume de suas memórias, Gilberto Amado - que adolescente foi empregado no Recife de uma firma de importações - fornece-nos uma lista surpreendente de objetos corriqueiros de consumo que o Brasil fazia vir de fora antes da Primeira Guerra Mundial (...). Essas alusões a um passado que me parece recente, pois dele me lembro com nitidez, ajuda-nos a perceber o que se passa atualmente com o filme. Como antigamente o palito, a manteiga, o automóvel ou a gasolina, o filme é ainda hoje considerado como algo que por definição deve ser estrangeiro. O fato de não termos cinema, ou de praticamente só realizarmos maus filmes, seria, de acordo com uma opinião tão arraigada que não sentia necessidade de explicitar-se, com freqüência, parte da realidade brasileira básica. $O$ Brasil não produz filmes como não produz cerejas, disse alguém simplificando esse ponto de vista. (GOMES, 1982a, p. 298, grifos do autor)

Rompendo, energicamente, com os múltiplos pré-juízos que decretavam a incapacidade cognitiva e técnica do brasileiro em realizar cinema com qualidade 
- uma afirmação que trazia, em si, a presença das diversas formulações ideológicas raciais e culturais acerca da debilidade intrínseca da formação social brasileira -, o crítico de cinema afirmava um novo juízo valorativo para o cinema feito por brasileiros: buscava compreendê-lo como manifestação que refletia as mais significativas contradições da cultura brasileira. Era o cinema que tornava possível a visibilidade das dinâmicas culturais profundas - a formalização das vontades e dos valores, das ideias e das ideologias - e da totalidade do mundo visível, em suas formas de vida e princípios, normas e instituições.

É importante ressaltarmos que, no interior do processo de compreensão do sentido e significado do cinema nacional, um traço significativo de sua crítica é o de ser e o de se considerar parte das contradições e alienações que narrava e buscava racionalmente compreender. São várias as passagens nas quais analisou a alienação que reinava solta na realidade brasileira, partindo da descrição de um comportamento ou experiência pessoal vivida. No artigo "Festejo Muito Especial", escrito em 1977, na Revista Cinema, nas comemorações dos 80 anos do cinema brasileiro, retratou a sua alienação pessoal como ponto de partida para a ordenação de um processo geral de alienação fruto do colonialismo cultural:

Meu caso pessoal é exemplar e deplorável. Em torno da década de 40 até meados da seguinte eu já me interessava muito por filmes, mas cinema brasileiro para mim era como se não existisse. Quando a gente fundava um clube ou uma revista é claro que se obedecia ao ritual de interesse por produto nosso: pura retórica sem qualquer conseqüência (...). Mais grave é lembrar - aí já nos cinqüenta - cuidando de criar uma Cinemateca Brasileira e totalmente descuidado de cinema brasileiro. É até difícil, hoje, me imaginar. Nessas condições, que eram a norma nos meios que freqüentava, quem ia saber a idade do cinema brasileiro, cuja própria e eventual existência não exercia sobre a intelligentsia o menor apelo? Nós ignorávamos o cinema brasileiro, mas tudo ocorria como se ele não nos ignorasse. Ele ficou espreita, à espera de uma distração, um descuido em nossos invólucros de colonizados culturais cinematográficos. Foi ele que se deu ao renovado trabalho de nos conquistar, agindo nas malhas da indústria ou nas tessituras artesanais. (GOMES, 1986b, p. 318 , grifo do autor)

Ao descrever as vicissitudes culturais na sua trajetória pessoal e de sua 
geração, Paulo Emílio Salles Gomes centrava a atenção ao problema da evasão da realidade e da árdua tarefa do intelectual em trabalhar com a "hostilidade da matéria" presente na sociedade brasileira. Se a evasão do confronto com a realidade, uma norma que reinava soberana na sociedade brasileira, era diagnosticada como consequência direta da submissão ao colonialismo cultural, a terapia formulava tanto a necessidade de superar os limites da retórica e da hipocrisia, quanto de aprofundar-se ainda mais no interior da densa e complexa matéria que forma a cultura brasileira. Logo, o novo juízo do crítico de cinema era composto pelo criticismo voltado para a análise histórica da formação do cinema no Brasil.

Nas suas análises sobre a vida cultural, em uma nação malformada, observou Paulo Emílio Salles Gomes que um dos exemplos culturais mais nítidos da alienação reinante era o generalizado sentimento negativo com relação ao cinema nacional. Exemplo maior desse processo era a chanchada, cuja dinâmica interna obedece a "uma harmoniosa combinação de pontos de vista entre os produtores e o público destes filmes brasileiros. Para ambos, cinema mesmo é o de fora, e outra coisa é aquilo que os primeiros fazem e o segundo aprecia" (GOMES, 1982a, p. 287). A compreensão da profundidade histórica da alienação e do impasse cultural, que impossibilitava qualquer tentativa de superação das contradições existentes na vida social brasileira, levaram Paulo Emílio Salles Gomes à formulação de uma série de questões decisivas a respeito da formação da cultura brasileira. Partindo da reflexão sobre uma faceta da cultura nacional, o cinema e a sua debilidade em se tornar um sistema, estabeleceu uma importante reflexão para pensar as vicissitudes da construção da cultura brasileira no interior da modernidade. Nas colunas de cinema no "Suplemento Literário", Paulo Emílio Salles Gomes formou a base analítica da presença de uma da dialética sem síntese existente no fluxo da vida social no Brasil: o desejo de evasão da realidade que "nos exprime e nos revela" e que se manifestada na disposição mental em "não ser" aquilo que se é em sempre "querer ser outro" (GOMES, 1986, p. 88).

2. A Crítica de Cinema no Labirinto da Modernidade: a trajetória do cinema brasileiro no subdesenvolvimento

Na violenta conjuntura do início dos anos 1970, Paulo Emílio Salles Gomes escreveu seus ensaios mais profundos e significativos acerca da especificidade do cinema e dos limites valorativos da cultura na realidade brasileira. Convém, antes, marcarmos bem o sentido das atividades intelectuais realizadas após a sua saída do "Suplemento Literário", em 1965, que, de certo modo, influenciaram a composição dos ensaios. Em 1964, Paulo Emílio Salles Gomes participou 
da tarefa de criação de cursos sobre cinema em universidades brasileiras e, como professor da disciplina "Cinema Brasileiro", na Universidade de Brasília, ministrou cursos sobre o cinema brasileiro, em especial, o de Humberto Mauro. $\mathrm{Na}$ introdução da sua tese de doutorado, singelamente chamada "Motivação", Paulo Emílio Salles Gomes descreveu o seu contato com o objeto de estudo nas seguintes palavras:

Não tinha idéia de que fosse preciso escrever tanto a propósito de Humberto Mauro. Conheci-o pessoalmente em 1940, mas não dei ao fato maior importância, pois naquele tempo - para minha vergonha - o cinema brasileiro, presente ou passado, não me interessava. Mais tarde fui vendo alguns de seus filmes, com vontade de revê-los e de conhecer os outros. (GOMES, 1974, p. 1-2)

Qual teria sido a sua motivação para escrever uma tese de doutorado sobre Humberto Mauro? Como explicar tal opção e qual teria sido o motivo da não realização de uma investigação, por exemplo, sobre o crítico André Bazin, que tanto o influenciou ao longo de sua vida? É possível compreendermos a opção realizada nas observações de Gilda de Mello e Souza, segundo a qual "o desinteresse de Paulo Emílio Salles Gomes pela teoria e pela moda é simétrico à atração do não-consagrado" (MELLO \& SOUZA, 1980, p. 214). Assim, afirma a autora e orientadora do "doutorando temporão", conforme costumava se autorretratar, que Paulo Emílio Salles Gomes se encaminhava naturalmente "para os mestres menores, os criadores tidos como primitivos, os períodos mais artesanais da história do cinema. É o caso de seu interesse por Jean Vigo, por Humberto Mauro" (idem). De fato, na sua obra, o ato crítico voltado para o estudo de autores avaliados como "menores" é amplo. Todavia, acreditamos que outra pista pode nos revelar o sentido da escolha de Humberto Mauro como objeto de pesquisa e tese de doutorado. Trata-se de entender tal opção como um fruto direto do empenho político e cultural que assumiu, nos anos 1960, em estudar sistematicamente o cinema brasileiro.

A tese de doutorado sobre Humberto Mauro representa um momento importante na vida de nosso autor. O desejo outrora compartilhado como Plínio Sussekind Rocha de "ver filmes e de falar sobre o cinema, de forma empenhada, militante" (GOMES, 1986a, p. 197), assumia uma nova perspectiva no começo da década de 1960. Nessa atmosfera cultural, podemos retratar o empenho cultural e político de Paulo Emílio Salles Gomes com a mesma fórmula que usara nos anos 1940 para exprimir o vínculo de seu mestre Plínio Sussekind Rocha com o cinema, efetuando apenas uma pequena variação: doravante iniciava o desejo de ver filmes brasileiros e de falar sobre o cinema brasileiro, de forma empenhada e militante. Em Argüição a Paulo Emílio Salles Gomes, Alfredo Bosi 
destacou uma questão fundamental a respeito da tese sobre Humberto Mauro, quando se refere ao "fascínio pela reconstituição da experiência" (BOSI, 1988, p. 142) existente nas reflexões de Paulo Emílio Salles Gomes. Nesse ensaio, pois sua tese é muito mais um ensaio do que um tratado científico, nosso autor procurou esclarecer o sentido da produção cinematográfica de Humberto Mauro, tentando decifrá-la mediante uma aproximação microscópica com a realidade brasileira, analisando as possibilidades objetivas e as capacidades subjetivas que ele e os membros da Companhia Phebo de Cataguases possuíam para fazer cinema, no final dos anos 1920. Um ensaio meticuloso, no qual interpretou o sentido da vida e da obra do personagem dentro de uma série de problemas significativos da sociedade brasileira. Retratou tanto os elementos subjetivos existentes no desejo dos pioneiros da Companhia Phebo de Cataguases em fazer cinema no Brasil, quanto a carência e fragilidade das possibilidades objetivas e técnicas para sua realização. Em precisa síntese acerca das condições objetivas e das disposições subjetivas dos agentes envolvidos, afirmou que:

(...) o estúdio era simpático, com o barracão de Agenor na Rua da Estação irreconhecível após as benfeitorias. Em suma, havia uma fachada e como atrás dela se produziu o renovado milagre de um filme atrás do outro, as pessoas comprometidas acreditavam, talvez, que a indústria cinematográfica nascera: Agenor se imaginava um produtor de cinema para o qual os estoques de café e as Buicks se tornariam atividades secundárias; Humberto se via realizando três filmes por ano, Adhemar e Pedro Lima aspiravam se integrar no esquema ilusório. A realidade ingrata, porém, logo chamava todos a si. (GOMES, 1974, p. 436)

Ao descrever o abismo que separava o desejo daqueles que procuravam criar o cinema brasileiro e as experiências possíveis de ser realizadas dentro da "realidade ingrata" que impunha a todos o seu peso coercitivo, apontava para a marca da precariedade do cinema no país dependente e atrasado.

É possível dizer que, em sua tese sobre o cinema de Humberto Mauro, compreendeu e diagnosticou tanto a singularidade da formação do desejo de fazer cinema no Brasil, como efetuou simultaneamente reflexões acerca da dinâmica cultural própria da sociedade brasileira no interior da modernidade. Ao retratar os desejos e os interesses pessoais, os disparates e as fantasias, as possibilidades técnicas e as capacidades pessoais dos envolvidos na produção dos filmes (a crença ilusória em querer ser outro, o exagero sempre contido nos argumentos, a fuga da realidade), Paulo Emílio Salles Gomes foi revelando novas feições a respeito da realidade brasileira. 
O retrato sobre a produção de Humberto Mauro é composto mediante a ideia de que a formação do cinema no Brasil é a história de um sistema permanentemente interrompido. Citando um artigo escrito por Pedro Lima, no final dos anos 1920, sobre o surgimento do cinema falado na Revista Cinearte, comenta Paulo Emílio Salles Gomes que: "aos olhos de Pedro Lima e Adhemar o filme falado apareceu como uma destruição dos próprios alicerces da estética cinematográfica que tinham apreendido laboriosamente durante anos" (GOMES, 1974, p. 349). No olhar atento de Paulo Emílio Salles Gomes, a produção cinematográfica de Humberto Mauro possibilitava o surgimento de certa "progressão orgânica de filme para filme", o início de uma formação técnica que necessitava de continuidade para poder adquirir e desenvolver uma capacidade fílmica mais apurada. Todavia, o surgimento dessa possibilidade técnica ocorria tardiamente, pois "quando o nosso cinema mudo alcança essa relativa plenitude, o filme falado já está vitorioso em toda parte" (GOMES, 1986, p. 31). Logo, a perda da continuidade acarretava o desfecho de uma capacidade técnica que, adquirida mediante seguidas tentativas e erros, era abandonada pela nova moda advinda do cinema estrangeiro.

Nos ensaios escritos entre o final dos anos 1960 e o início dos 1970, sobretudo em Pequeno Cinema Antigo, Panorama do Cinema Brasileiro: 1896/1966 e Cinema: trajetória no Subdesenvolvimento, Paulo Emílio Salles Gomes deu sequência ao estudo acerca da incapacidade do cinema formar no Brasil um sistema e uma tradição, como chegou a alcançar a literatura. Sua tese era a de que a trajetória do cinema era caracterizada por raros momentos de exceção de vitalidade e organicidade que intercalam uma resistente norma da esterilidade e mediocridade:

\begin{abstract}
O Brasil, que importava de tudo - até caixão de defunto e palito -, abriu alegremente as portas para a diversão fabricada em massa e certamente não ocorreu a ninguém a idéia de socorrer nossa incipiente atividade cinematográfica. O filme brasileiro primitivo foi rapidamente esquecido, rompeu-se o fio e nosso cinema começou a pagar o seu tributo à prematura e prolongada decadência tão típica do subdesenvolvimento. Arrastando-se na procura da subsistência, tornou-se um marginal, um pária numa situação que lembra a do ocupado, cuja imagem refletiu com freqüência nos anos vinte, provocando repulsa ou espanto. (GOMES, 1986, p. 89)
\end{abstract}

Um sistema frágil e interrompido, que é permanentemente subordinado à cultura europeia e norte-americana, tal era a imagem que Paulo Emílio Salles Gomes construiu e difundiu na atmosfera cultural e política dos anos 1960. 
Um argumento que será plenamente desenvolvido nos seus ensaios que buscavam revelar os fortes vínculos entre o cinema brasileiro e o subdesenvolvimento, bem como demonstrava a presença do drama próprio da formação da cultura em um país periférico: estar em constante estado de subordinação cultural e atraso histórico. O que chamou de "a bela época do cinema brasileiro", na sua tese sobre o cinema de Humberto Mauro, estava, pois, condenada a ser esquecida e posta de lado pelas novas e fulminantes invenções técnicas produzidas na Europa e nos Estados Unidos. Assim, a sensação quase inevitável da "mediocridade reinante" deveria ser entendida como "resultado direto de uma conjuntura muito precisa. Através do exame de condição dos distribuidores, produtores, encarregados de cinemateca, críticos e ensaístas delineiam-se com precisão as linhas de uma situação colonial" (GOMES, 1982a, p. 291).

Uma situação colonial, tal era a síntese teórica que usara para nomear o pântano em que estava inserida a vida cultural e política brasileira. Logo, um problema que, iniciado nas colunas do "Suplemento Literário" e na sua tese de doutorado sobre o cinema de Humberto Mauro, alcançaria o pleno desenvolvimento teórico no ensaio Cinema: trajetória no Subdesenvolvimento, onde Emílio Salles Gomes retomou várias questões e problemas que desenvolveu:

O cinema norte-americano, o japonês e, em geral, o europeu nunca foram subdesenvolvidos, ao passo que o hindu, o árabe ou o brasileiro nunca deixaram de ser. Em cinema o subdesenvolvimento não é uma etapa, um estágio, mas um estado: os filmes dos países desenvolvidos nunca passaram por essa situação, enquanto os outros tendem a se instalar nela. O cinema é incapaz de encontrar dentro de si próprio energias que the permitam escapar à condenação do subdesenvolvimento, mesmo quando uma conjuntura particularmente favorável suscita uma expansão na fabricação de filmes. (GOMES, 1986, p. 85)

Podemos dizer que, nesse ensaio, o processo cognoscitivo iniciado nos anos 1960 alcançou o seu ponto mais extremo e significativo. A afirmação de que a compreensão do cinema no Brasil somente poderia ser avaliada dentro do sentido e o significado que a cultura possui em um país periférico e subdesenvolvido, no qual a "situação colonial" persistia em se manter sem profundas alterações nos valores e nas ações sociais, era a síntese da dialética que sempre procurou compreender no seu empenho cultural e político. Como apontou Antonio Candido, no centro desse ensaio está a compreensão do "significado nacional de nossa cultura" (CANDIDO, 1980, p. 17), um problema que levou o crítico de cinema a dirigir sua atenção e esforços para o entendimento do 
advento da nação e da sua posição no mundo moderno. Efetuando uma análise comparativa entre a "diferença e a parecença" do cinema brasileiro para com outros cinemas subdesenvolvidos, como o hindu e o árabe, afirmou que:

Essa evocação de alguns traços das situações cinematográficas subdesenvolvidas mais importantes do mundo pode servir de introdução útil à nossa. A diferença e a parecença nos definem. A situação cinematográfica brasileira não possui um terreno de cultura diverso do ocidental onde possa deitar raízes. Somos um prolongamento do Ocidente, não há entre ele e nós a barreira natural de uma personalidade hindu ou árabe que precise ser constantemente sufocada, contornada e violada. Nunca fomos propriamente ocupados. Quando o ocupante chegou o ocupado existente não the pareceu adequado e foi necessário criar outro. A importação maciça de reprodutores seguida de cruzamento variado assegurou o êxito na criação do ocupado, apesar da incompetência do ocupante agravar as adversidades naturais. A peculiaridade do processo, o fato de o ocupante ter criado o ocupado aproximadamente à sua imagem e semelhança, fez deste último, até certo ponto, o seu semelhante (...). Nossos acontecimentos históricos - independência, república, revolução de trinta são querelas de ocupantes nas quais o ocupado não tem vez. O quadro se complica quando lembramos que a metrópole de nosso ocupante nunca se encontra onde ele está, mas em Lisboa, Madri, Londres ou Washington. (GOMES, 1986, p. 87-88)

Descrevendo tanto o longo processo de racionalização que resultou na formação do capitalismo na Europa, quanto a uma nova leitura do processo de colonização no Brasil, apontou para o problema conjunto do esquecimento do passado na formação da cultura brasileira e do desejo das elites brasileiras em efetuar a fuga da realidade local e o transplante ideológico em direção aos valores e formas de prestígio criadas nas metrópoles. Na composição desse quadro, elaborou um outro problema específico da cultura brasileira:

Não somos europeus nem americanos do norte, mas destituídos de cultura original, nada nos é estrangeiro, pois tudo o é. A penosa sensação de nós mesmos se desenvolve na dialética rarefeita entre o não ser e o ser outro. O filme brasileiro participa do mecanismo e o altera através de nossa incompetência criativa em copiar. O fenômeno cinematográfico no Brasil testemunha e delineia muita vicissitude nacional. (GOMES, 1986, p. 88) 
Para Antonio Candido, esse trecho "é o centro da reflexão de Paulo Emílio Salles Gomes", na qual podemos vislumbrar sem rodeios o drama exterior e interior que nos assola, isto é, "os dilaceramentos de consciência que a situação traz" (CANDIDO, 1980, p. 4).

De fato, Antonio Candido argumentou, com precisão, para o drama maior presente na reflexão mais consistente de Paulo Emílio Salles Gomes, os dilemas oriundos do hegemônico processo de alienação material e espiritual que marca tanto os ocupantes, como os ocupados, na sociedade brasileira. Essa é a principal contradição que envolve toda a cultura brasileira: a de ser e, ao mesmo tempo, não ser parte da cultura ocidental. Uma dupla alienação que envolve a todos e que acaba cobrando um alto preço da existência no interior da sociedade na qual os indivíduos não se reconhecem em si e, muito menos, agem em conjunto para a construção de uma sociedade moderna e democrática. $\mathrm{Na}$ complexa e contraditória formação social brasileira, o cinema poderia contribuir para desfazer valores e ideologias, ações sociais e relações culturais, mentalidades e comportamentos, mediante a sua especificidade: como manifestação da superfície, "qualquer filme exprime ao seu jeito muito do tempo em que foi realizado" (GOMES, 1986, p. 98). Como expressão cultural do tempo histórico, a apaixonada defesa do cinema efetuada por Paulo Emílio Salles Gomes sempre enfatizou a capacidade fílmica de permitir ao indivíduo moderno o contato com a sua realidade física e com os valores existentes, o que permitiria o desenvolvimento de novos processos de construção da consciência de si mesmo, da dinâmica cultural da sua sociedade e dos enfrentamentos das contradições do tempo histórico.

Para Paulo Emílio Salles Gomes, o pecado mortal das elites intelectuais no Brasil era a relutância e o consequente distanciamento frente aos problemas da formação da cultura brasileira. No seu raciocínio, tal pecado reside na posição distante da realidade, que impossibilita o intelectual de ser um intérprete da racionalidade existente ou que deveria ser criada dentro da nação. Utilizando as palavras de Domenico Losurdo sobre a responsabilidade dos intelectuais, é possível dizer que o alvo do discurso de Paulo Emílio Salles Gomes estava centrado na crítica à "ilusão da imaculada posição de estranhamento das teorias elaboradas com respeito à luta político-social do tempo" e na necessidade fundamental da "interrogação sobre as consequências objetivas dos discursos por eles desenvolvidos" (LOSURDO, 1997, p. 97). Nas colunas de crítica de cinema na Revista Clima e no "Suplemento Literário", na tese de doutorado e nos ensaios, Paulo Emílio Salles Gomes compôs um estilo de pensamento que sempre buscava expor a presença da alienação e da ideologia nas ações e relações sociais, processos e estruturas de poder, ao mesmo tempo, que enfatizava a necessidade de compreensão da realidade e ação política dos intelectuais. 
Um esforço teórico e prático que afirmou, já nos anos 1930 e 1940, quando afirmou ser o "destino" da sua geração participar do "desaparecimento de um Brasil formal e do nascimento de uma nação" (GOMES, 1945, p. 293).

Refletindo o clima temporal de promessas existentes no início dos anos 1960 e a trágica atmosfera política da década de 1970, observou que:

A deterioração da conjuntura estimulante dos inícios dos anos sessenta fez com que o público intelectual que corresponde hoje ao daquele tempo se encontre órfão de cinema brasileiro e voltado inteiramente para o estrangeiro onde julga às vezes descobrir alimento para sua inconfidência cultural. $\mathrm{Na}$ realidade ele encontra apenas uma compensação falaciosa, uma diversão que o impede de assumir a frustração, primeiro passo para ultrapassá-la. Rejeitando uma mediocridade, com a qual possui vínculos profundos, em favor de uma qualidade importada das metrópoles com as quais tem pouco a ver, esse público exala uma passividade que é a própria negação da independência a que aspira. Dar as costas ao cinema brasileiro é uma forma de cansaço diante da problemática do ocupado e indica um dos caminhos de reinstalação na ótica do ocupante. A esterilidade do confronto intelectual e artístico que o filme estrangeiro prodiga faz da parcela de público que nos interessa uma aristocracia do nada, uma entidade em suma muito mais subdesenvolvida do que o cinema brasileiro que desertou. Não há nada a fazer e não ser constatar. Este setor de espectadores nunca encontrara em seu corpo músculos para sair da passividade, assim como o cinema brasileiro não possui força própria para escapar ao subdesenvolvimento. Ambos dependem da reanimação sem milagre da vida brasileira e se reencontrarão no processo cultural que daí nascerá. (GOMES, 1986, p. 100)

Estabeleceu, portanto, um problema decisivo sobre o processo cultural brasileiro: a falta de identificação de vastos setores da sociedade com a matéria social ao seu redor. Se retomarmos a sua famosa observação de que "convém lembrar, ainda, por menos agradável que se considere a asserção, que o cinema brasileiro nos exprime e revela" (GOMES, 1982a, p. 150), como podemos entender a aversão que se sente por tal produto cultural? Segundo nosso autor, uma possível explicação para esse fenômeno pode ser vista na manipulação da memória e nos processos de identificação com os valores culturais.

Os ensaios de Paulo Emílio Salles Gomes sobre os múltiplos nexos entre o 
cinema e a situação social podem ser vistos como tentativas sistemáticas de colocar o problema da memória e do esquecimento do passado como um campo de batalha pela conquista do sentido do presente histórico. $\mathrm{O}$ apelo extremo voltado para a identificação do brasileiro para com o seu cinema seria um passo fecundo para rompermos com a alienação cultural. Um novo sopro de esperança que poderia nascer tanto do ato de compreensão do que nos cerca e do que realmente somos, como no abandono dos mitos, dos valores envelhecidos e infrutíferos e das estéreis representações da realidade cultural brasileira. Logo, o cinema poderia ser uma meio cultural que promovesse a ruptura com as explicações históricas sobre o passado cultural e falsificavam sentido do presente. Tal era o argumento mais profundo dos seus ensaios sobre o cinema brasileiro e a cinemateca, dirigidos à recuperação do passado contido nos rolos dos filmes e não existente na fraca memória histórica dos indivíduos, em suas mentalidades evasivas e sempre voltadas à identificação da moda valorativa advinda do exterior.

\section{O Papel do Intelectual Empenhado}

Expondo as contradições e ambiguidades contidas na produção do cinema como condições próprias da vida cultural brasileira, Paulo Emílio Salles Gomes buscava ressaltar que a tarefa do intelectual em um país como o Brasil é transformar a realidade social em problemas. Seguindo uma observação de Antonio Candido, é possível dizer que, nos anos 1970, Paulo Emílio Salles Gomes desempenhou um papel cultural próximo àquele efetuado por Mário de Andrade, que consistia em formular ideias extremas e radicais a respeito da cultura nacional. No curso do ímpeto valorativo do cinema brasileiro, Paulo Emílio Salles Gomes afirmou a valorização do cinema nacional em detrimento das fitas estrangeiras (posição que defendeu ao extremo, quando disse que não mais iria ver filme que não fosse nacional). Seu intento era fazer com que os brasileiros, assistindo ao cinema nacional, pudessem refazer o contato com a realidade brasileira, de modo que a visão das imagens locais pudesse ser transformada em contemplação e reflexão, passos fundamentais para uma possível teorização dos problemas nacionais. A visualização de quem somos seria o primeiro passo que poderia desencadear impulsos pedagógicos e catárticos que poderiam permitir uma reconstrução valorativa da sociedade brasileira. Um processo que seria novamente interrompido pelas forças sociais que reafirmavam a presença do golpismo, do autoritarismo e do elitismo na história brasileira.

No artigo "Contra Fato Há Argumento", publicado na Revista Argumento durante a trágica conjuntura política do início dos anos 1970, Paulo Emílio Salles Gomes ressaltou novamente a importância do papel do intelectual: 
Os obstáculos que eventualmente encontramos e os estímulos que recebemos serão igualmente indicativos da utilidade de nossa função. Muito intelectual brasileiro foi arrancado de seu mundo e é preciso que encontre um terreno onde possa novamente se enraizar. A limitação de nosso campo poderá ainda ser restringida, mas sempre haverá um papel a ser cumprido pelo intelectual que resolva sair da perplexidade e se recuse a cair no desespero. Nascemos sem ilusões e não está em nosso programa nutri-las. A independência custa caro e não encoraja as subvenções. Não temos propriamente o que vender, mas nos achamos em condições de propor um esforço de lucidez. Esta não é artigo de luxo ou de consumo fácil, mas em qualquer tempo é alimento indispensável pelo menos para alguns. Sua raridade é, aliás, sempre provisória; tudo o que a lucidez revela tende a se transformar em óbvio. Contra fato há argumento. (GOMES, 1986c, p. 108)

Argumentar passou a ser a única possibilidade de expressão e ação política para a sua geração intelectual, aquela que iria sofrer, na velhice, a segunda desventura de novamente ter de viver em um estado político ditatorial. Um empenho tanto político como cultural que Paulo Emílio Salles Gomes realizou em boa parte de sua vida, no interior das longas "noites do medo que periodicamente nos são impostas" (GOMES, 1986d, p. 210). Nas sucessivas noites do medo imposto pelas forças sociais dominantes, um traço saliente da sua postura intelectual é a contínua reflexão crítica sobre os acontecimentos pessoais e históricos vivenciados no passado recente. O recurso analítico de reelaborar as experiências do passado, cuja principal intenção é a de evitar a supressão da história, aparece em toda sua obra como resultado de uma espécie de catarse crítica, mediante a qual os temores e as ambições do passado eram reavaliados em um novo patamar cognitivo. Podemos compreender a disposição do intelectual para a crítica e a autocrítica na análise do filme Hiroshima meu amor. Na sua abordagem do filme, Paulo Emílio Salles Gomes refletiu aquilo que chamou de "meus pecados públicos", no caso, o grau de cumplicidade e satisfação que teve no passado com a eclosão da bomba nuclear sobre a cidade de Hiroshima. Partindo da interrogação de qual seria o grau de cumplicidade que teria com o acontecimento ocorrido em 1945, acaba lançando uma profunda interrogação sobre a responsabilidade dos intelectuais para com o sentido da história:

Quando eu vi a fita Hiroshima meu amor eu entendi, mas entendi profundamente (desta vez fui certamente muito mais sensível do que a média dos espectadores), eu entendi a impossibilidade em que se encontraram os 
responsáveis pela fita de realizar uma obra de reconstituição dramática da tragédia de Hiroshima. E admirei também profundamente a solução que deram ao problema, compondo um poema de amor cuja abertura é o combate entre a lembrança-presença apocalíptica da bomba e os esforços inúteis para registrar e avivar sua memória coletiva em monumentos, museus, turismo ou filmes. Poema que por sua vez é meditação intrincada, sinuosa e cruel a respeito de nossas lembranças e esquecimentos individuais. A incapacidade, a impotência, a paralisação, o pudor dos autores de Hiroshima meu amor diante da Hiroshima de maio de 1945 faz acompanhar a emoção artística e humana que nos envolve do gosto forte do remorso e da vergonha. (GOMES, 1986e, p. 237)

Que força conduz o intelectual a expurgar os seus demônios em público, senão a autocrítica que permite o balanço da herança histórica do passado? Que obrigação maior existe no trabalho intelectual do que refletir sobre a sua posição concreta no mundo? Na tomada de consciência histórica, o intelectual encontra o sentido do seu papel social. É o que afirmou Domenico Losurdo, pois "a consciência histórica é a condição preliminar para que o intelectual possa pôr-se, no exercício mesmo da atividade intelectual, como sujeito moral que tem defronte de si conflitos e responsabilidade iniludíveis e que, na avaliação do passado, não se invoca fora da cadeia ininterrupta da responsabilidade" (LOSURDO, 1997, p. 97). Se aceitarmos essa abordagem sobre o dever moral e político presente no papel do intelectual, podemos afirmar que Paulo Emílio exerceu com dignidade o seu papel intelectual na sociedade brasileira.

Desse modo, podemos dizer que sua personalidade intelectual sempre foi forjada no confronto com a realidade brasileira e com os problemas oriundos da crise da modernidade, tentando ora promover uma revolução socialista democrática no Brasil, ora buscando compreender os complexos e obscuros contornos da cultura e da sociedade brasileira através da sua crítica de cinema. Um ato próprio dos intelectuais que, frente ao medo, não regrediram, e que utilizaram o discurso e a ação, o caráter e a paixão como armas de combate para o advento de novas ideias e conceitos, princípios valorativos e instituições sociais. É possível dizer que o empenho político e cultural de Paulo Emílio Salles Gomes era formado e adquiria maior profundidade conforme se aproximava dos dilemas e conflitos existentes em seu tempo histórico, pois, como afirma um belo verso do poeta alemão Hölderlin, que aqui utilizamos para concluir o seu retrato final, a postura do ser humano e do intelectual se eleva na medida em que pensa e age no interior das tragédias e das catástrofes do seu tempo, pois "onde está o perigo, cresce também aquilo que te salva" (apud BERING, 1978, p. 331). 
Abstract: The aim of this paper is to understand the intellectual role played by Paulo Emilio Salles Gomes in Brazilian society. Based on the analysis of his film criticism on the newspaper "O Estado de São Paulo" in the fifties, I seek to characterize the process of constructing the cultural and political commitment toward the building of a democratic society in Brazil, who gave detailed analysis of the cinema and reality in the sixties and seventies decades of the 20th Century.

Keywords: Paulo Emílio Salles Gomes, Modernity, politic and cultural Commitment, Criticism of film.

\section{Referências}

BERING, D. Die Intellektuellen. Geschichte eines Schimpfwortes. Stuttgart: Ernst Klett-Cotta Verlag, 1978.

BOSI, A. Céu, Inferno. Ensaios de crítica literária e ideológica. São Paulo: Editora Ática, 1988.

CANDIDO, A. "Cinema: trajetória no subdesenvolvimento". Filme Cultura, Embrafilme, n. 35/36, 1980, p. 2-18.

. "Informe Político", In: C. A. Calil e M. T. Machado, (orgs.), Paulo Emílio Salles Gomes: um intelectual na linha de frente. São Paulo: Brasiliense/ Embrafilme, 1986.

\section{. Recortes. São Paulo: Companhia das Letras, 1993.}

GOMES, P. E. S. “Depoimento”, In: M. Neme (org.) Plataforma da nova geração. Porto Alegre: Globo, 1945.

. Humberto Mauro, Cataguases, Cinearte. São Paulo: Editora Perspectiva/Edusp, 1974.

. "Discurso de Formatura, 1944". Ensaios de Opinião, n. 2-4, 1978,

p. 17-20.

. Crítica de Cinema no Suplemento Literário, vol. I. Rio de Janeiro:

Paz e Terra/Embrafilme, 1982.

. Crítica de Cinema no Suplemento Literário, vol. II. Rio de Janeiro:

Paz e Terra/Embrafilme, 1982a.

. Cinema: trajetória no subdesenvolvimento. Rio de Janeiro: Paz e Terra, 2a edição, 1986. 
. "Plínio Sussekind Rocha", In: C. A. Calil e M. T. Machado (orgs.), Paulo Emílio Salles Gomes: um intelectual na linha de frente. São Paulo: Brasiliense/Embrafilme, 1986a.

. "Festejo muito pessoal", In: C. A. Calil e M. T. Machado (orgs.), Paulo Emílio Salles Gomes: um intelectual na linha de frente. São Paulo: Brasiliense/Embrafilme, 1986b.

. "Contra fato há argumento", In: C. A. Calil e M. T. Machado (orgs.), Paulo Emílio Salles Gomes: um intelectual na linha de frente. São Paulo: Brasiliense/Embrafilme, 1986c.

. "Arnaldo Pedroso d'Horta", In: C. A. Calil e M. T. Machado (orgs.), Paulo Emílio Salles Gomes: um intelectual na linha de frente. São Paulo: Brasiliense/Embrafilme, 1986d.

. "Hiroshima minha dor", in C. A. Calil e M. T. Machado (orgs.), Paulo Emílio Salles Gomes: um intelectual na linha de frente. São Paulo: Brasiliense/Embrafilme, 1986e.

KAHNS, C. "Depoimento de Paulo Emílio Salles Gomes Salles Gomes". Ensaios de Opinião. São Paulo, n. 2-4, 1977, p. 21-22.

KRACAUER, S. La massa come ornamento. Napoli: Prismi, 1982.

ciones Paidós, 1989.

. Teoria del cine. La redención de la realidad física. Barcelona: Edi-

LEC, S. J. Pensieri spettinati. Bologna: Tascabili Bompiani, 2001.

LOSURDO, D. "Gli intellettuali e il conflitto: responsabilità e coscienza storica". Rivista di Filosofia, Bologna: II Mulino, vol. LXXXVIII, n. 1, 1997, p. 79-98.

MACHADO, L. G. “Depoimento”, In: M. Neme (org.), Plataforma da nova geração. Porto Alegre: Globo, 1945.

MELLO e SOUZA, G. de. Exercícios de leitura. São Paulo: Livraria Duas Cidades, 1980.

ROCHA, P. S. "Carta sobre Fantasia”. Clima, n. 5, 1941, p. 83-87. 